\title{
Fuzzy regression model of the impact of technology on living standards
}

\author{
Yury A. Zelenkov
}

E-mail: yzelenkov@hse.ru

\section{Elizaveta V. Lashkevich}

E-mail: evlashkevich@edu.hse.ru

National Research University Higher School of Economics

Address: 20, Myasnitskaya Street, Moscow 101000, Russia

\begin{abstract}
This paper proposes a model of the impact of technology on the standard of living based on fuzzy linear regression. The Human Development Index (HDI) was chosen as a dependent variable as an indicator of the health and well-being of the population. The explanatory variables are the Network Readiness Index (NRI), which measures the impact of information and communication technologies (ICT) on society and the development of the nation, and the Global Innovation Index (GII), which measures the driving forces of economic growth. The analysis is based on data for 2019 for four groups of countries with different levels of GDP per capita. For developed countries, the positive and balanced impact of innovation and ICT on living standards has been confirmed. For two groups of developing countries (upper and lower middle income), the GII coefficient was found to be negative. A more indepth analysis showed that this is due to the state of political and social institutions. This fact means that without a simultaneous increase in the maturity of institutions, stimulation of other areas of innovative development (education, knowledge and technology, infrastructure) leads to a decrease in the quality of life.
\end{abstract}

Key words: living standards; technical development; fuzzy regression; quantitative models.

Citation: Zelenkov Yu.A., Lashkevich E.V. (2020) Fuzzy regression model of the impact of technology on living standards. Business Informatics, vol. 14, no 3, pp. 67-81.

DOI: $10.17323 / 2587-814 X .2020 .3 .67 .81$ 


\section{Introduction}

$\mathrm{M}$ ost countries declare that the highest value is the human being, his or her rights, and freedom (see, for example, Article 2 of the Constitution of the Russian Federation). Therefore, many modern politicians and researchers believe that the main goal of the state is the maximum wellbeing of citizens, indicators of which are the quality of life, equal access to services, the possibility of self-realization, participation in decision-making, etc. $[1,2]$. One of the catalysts promoting well-being, along with political and social institutions, is technological progress [3]. Therefore, it is essential to understand how the use of technology relates to living standards and human development.

The goal of this work is to build quantitative models of the impact of technology on the well-being of citizens of different countries. We pay special attention to modern digital technologies, the use of which, according to many practitioners and researchers, will lead to another industrial revolution, which can radically change both state and social structures and individual behavior models [4]. Therefore, we chose the Human Development Index (HDI ${ }^{1}$ ) as the indicator under study, and the Network Readiness Index $\left(\mathrm{NRI}^{2}\right)$ and the Global Innovation Index $\left(\mathrm{GII}^{3}\right)$ as explanatory variables. The study was conducted on data from 2019.

We also believe that the impact of technology on well-being is different for developed and developing countries $[5,6]$. To identify groups of countries, we used the World Bank approach based on GDP per capita [7] and divided the countries under study into four groups.

The results obtained confirm the positive and balanced impact of innovation and information and communication technologies (ICT) on the standard of living for developed countries. For two groups of developing countries (upper and lower middle income), the GII coefficient was found to be negative. A more in-depth analysis showed that this is due to the state of political and social institutions. This fact means that without a simultaneous increase in the maturity of institutions, stimulation of other areas of innovative development (education, knowledge and technology, infrastructure) leads to a fall in the living standards in developing countries.

\section{Review of the literature}

Most researchers studying the impact of ICT at the country level have focused on increasing productivity as measured by GDP. Many empirical works have proven that investment in ICT leads to GDP growth in developed countries [5], and the effect of ICT is faster than the effect of other technologies [8]. However, no such positive relationship between ICT and GDP has been found in developing countries. The authors of [5] explain this by the lack of appropriate complementary resources and technologies that must complement ICT to ensure sustainable growth.

Later studies $[6,9]$ showed that the impact of ICT is not limited to productivity growth (i.e. GDP). On the contrary, the use of ICTs also improves the well-being of the country by helping citizens develop their social capital and achieve social equity, and also ensures equal access to health services and education for all groups of the population. Also, the report [10] argues that a networked environment that makes it easier to develop and sell services can create 140 million new jobs and lift 160 million people out of poverty.

However, not all countries with a similar ICT structure (ratio of a fixed to mobile phones,

\footnotetext{
1 http://hdr.undp.org

2 https://networkreadinessindex.org

${ }^{3}$ https://www.globalinnovationindex.org
} 
access to the Internet, etc.) improve their level of well-being in the same way [6]. This can be explained by the influence of factors such as political and social characteristics, the level of trust, the development of the legislation and regulations.

Thus, more research is needed on the impact of ICT on living standards. Therefore, in this paper, we propose a model of the effects of innovation (measured through the global innovation index, GII), including ICT (Networked Readiness Index, NRI), on the development of the nation (Human Development Index, HDI).

The Human Development Index (HDI) is a statistical tool that integrates three key dimensions: health and life expectancy, educational attainment, and living standards. HDI is calculated as the geometric mean of the normalized indices over these three dimensions [11]. HDI has been published by the United Nations Development Program since 1990 [12]. It is a standard tool for comparing the living standards of different countries. Depending on the HDI value, countries are usually classified according to their level of development: very high, high, medium, and low.

HDI can also be considered as an indirect indicator of the maturity of social institutions since they contribute to human development [13]. Along with an important instrumental role in creating and strengthening certain abilities, social institutions shape individual preferences and behavior, since people cannot be considered completely autonomous. Furthermore, the relationship between people and institutions determines whether a society is peaceful, cohesive, and inclusive.

The Networked Readiness Index (NRI) is a holistic framework for assessing the multifaceted impact of information and communication technologies on society and the development of a nation [14]. The NRI identifies three key dimensions for ICT: individuals/ society, enterprises, and governments. It contains elements describing the application of ICTs in national economies, including, for example, the quality of regulations.

NRI is published by the World Economic Forum in partnership with the World Bank, INSEAD Business School and Cornell University. In 2019, the index model was revised, and today it includes four main dimensions (technology, people, government, and influence), each of which is a combination of three sub-indices [14].

However, when studying the impact of technology on the well-being of nations, it would be illogical to limit the research only to the consideration of ICT, since significant advances are being observed in other industries - medicine, agriculture, space research, etc. Therefore, we included the Global Innovation Index (GII) in our model, which is based on an extensive database of detailed indicators for the economies of different countries [15]. GII is published by Cornell University, INSEAD and the World Intellectual Property Organization (a specialized agency of the UN).

Recognizing the pivotal role of innovation in driving economic growth and prosperity, the GII includes indicators that go beyond standard innovation measures, such as the level of research and development. The GII is based on two sub-indices, the Innovation Input SubIndex and the Innovation Output Sub-Index, each of which is based on seven key elements. Five elements describe the characteristics of the national economy that drive innovation: (1) human capital and research, (3) infrastructure, (4) market sophistication, and (5) business sophistication. Two elements reflect the actual results of innovation: (6) knowledge and technology outputs and (7) creative outputs. To calculate these indices, 80 different indicators are used. 


\section{Model, data and method}

Our study is based on the following hypothesis: the national innovation system (as measured by GII) and the development of ICT in the country (as measured by the NRI) positively affect the level of well-being of citizens (as measured by the HDI), but this effect is different for groups of countries that differ in GDP per capita.

Figure 1 presents a research model showing the indices, their dimensions and relationships between the indices.
The required data was downloaded from the sources provided in the Introduction. For the study, we used the latest actual values of the indices published in 2019; the total sample contains data for 112 countries. In addition to the values of the listed indices, the sample also included the GDP per capita obtained from the World Bank website. Table 1 presents the statistical characteristics of the indices, and Figure 2 - the study of their mutual correlation. In the diagonal elements of the matrix in Figure 2, the distributions of the corresponding indices are shown, in the cells above the

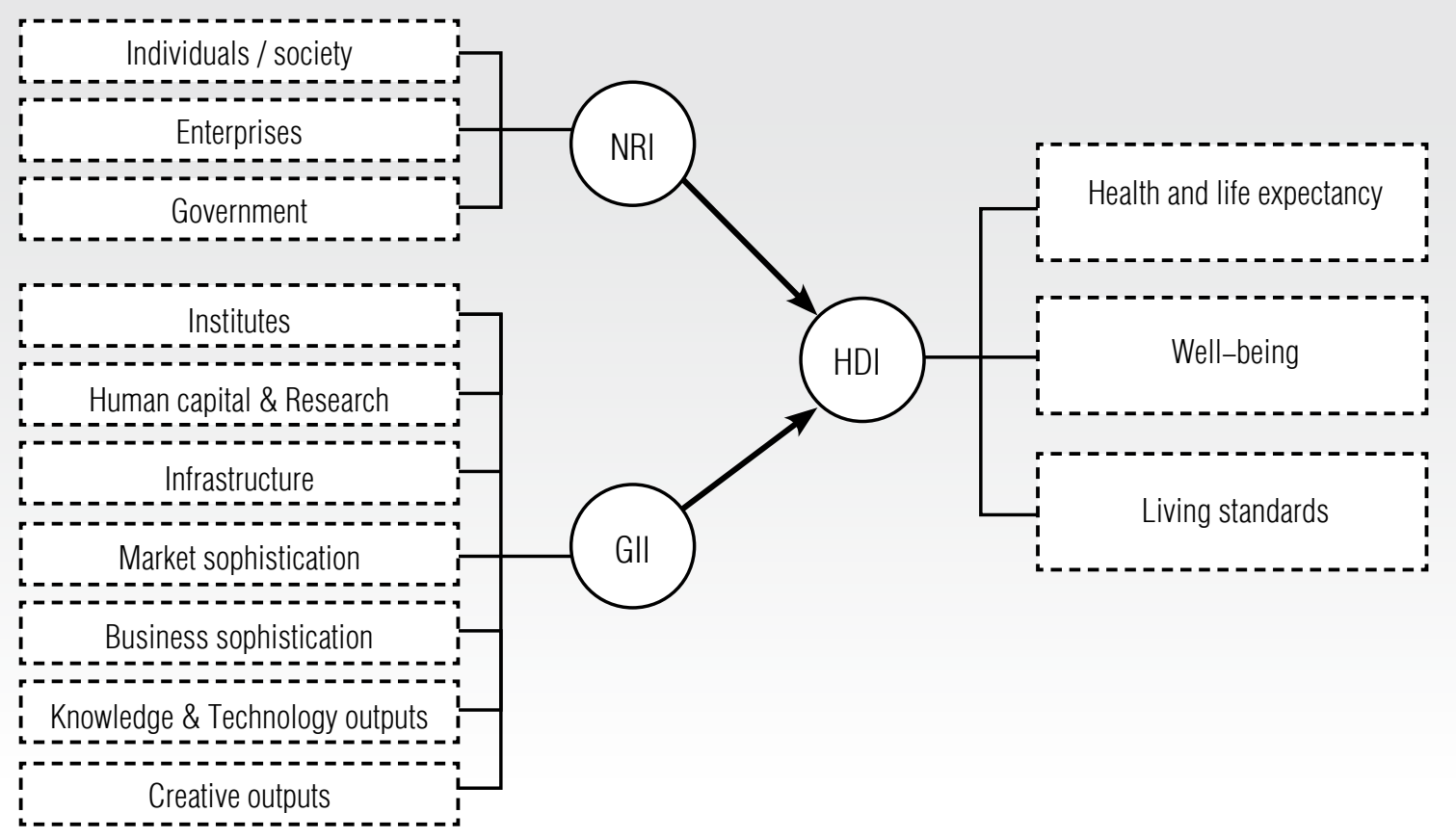

Fig. 1. Research model

Descriptive statistics

Table 1.

\begin{tabular}{c|c|c|c|c|c|c|c} 
Index & Min & Max & Mean & Standard deviation & Median & Skewness & Kurtosis \\
\hline HDI & 0.43 & 0.95 & 0.76 & 0.13 & 0.79 & -0.65 & -0.46 \\
\hline GII & 20.40 & 67.20 & 37.56 & 11.70 & 34.45 & 0.68 & -0.65 \\
\hline NRI & 22.07 & 82.65 & 52.47 & 16.54 & 51.17 & 0.10 & -0.91 \\
\hline
\end{tabular}




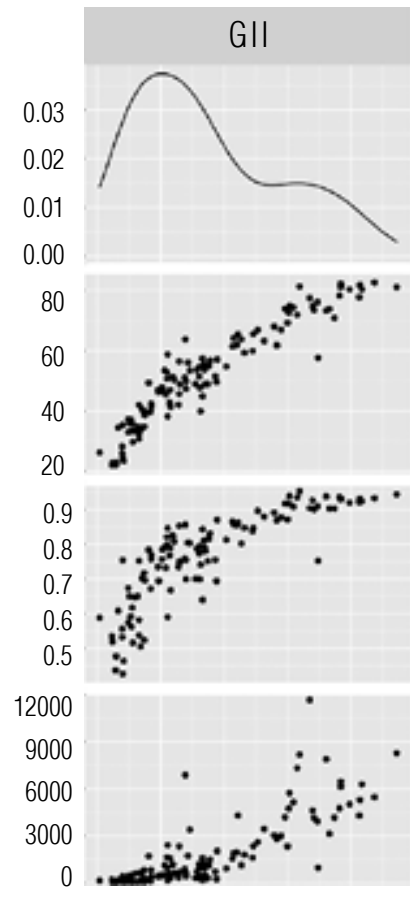

$\begin{array}{llllll}20 & 30 & 40 & 50 & 60 & 20\end{array}$

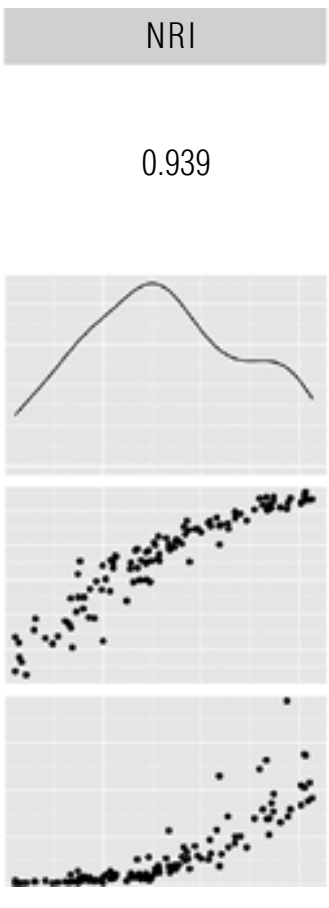

$60 \quad 80$

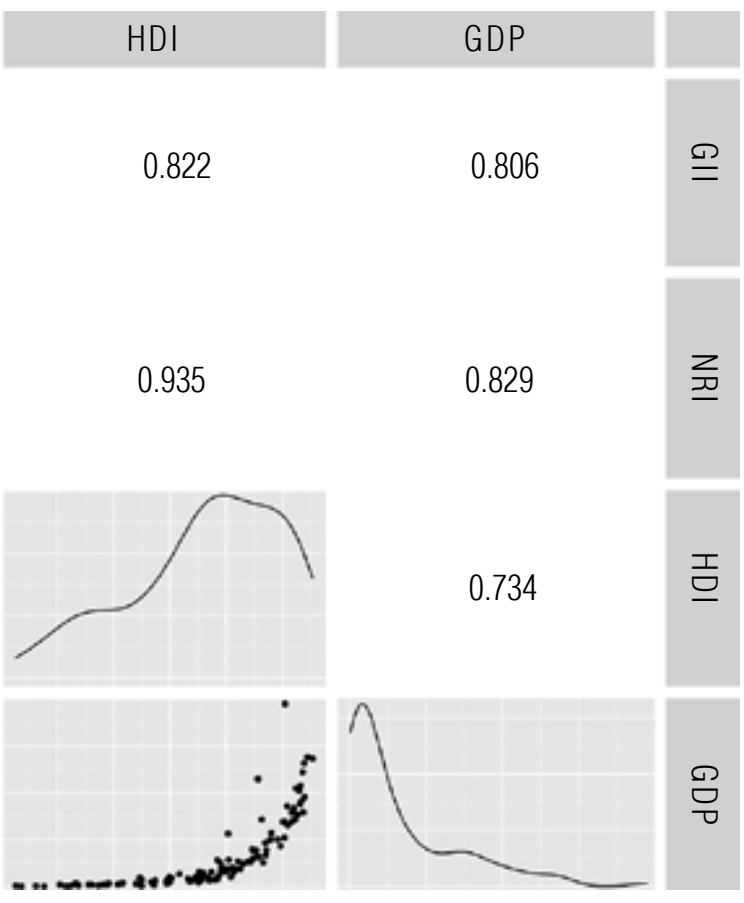

$\begin{array}{llllllllll}0,5 & 0,6 & 0,7 & 0,8 & 0,9 & 0 & 3000 & 6000 & 9000 & 12000\end{array}$

Fig. 2. Indices correlation

diagonal - the pair correlation coefficients, in the cells below the diagonal - scatter diagrams.

As follows from Figure 2, all the variables are strongly correlated, $R^{2}$ is not less than 0.7 , and in some cases, even close to one. The scatter plots show that the GII and NRI indices are significantly correlated with HDI, with an $R^{2}$ value greater than 0.8 . There is also a strong pairwise correlation between GII and NRI, potentially leading to multicollinearity.

All 112 countries were divided into four groups on base of value GDP per capita (Table 2) in accordance with the classification of the World Bank [7], which is used to compile the GII index. Figure 3 shows the distribution of

Groups of countries according to the value of GDP per capita

\begin{tabular}{c|c|c|c|c} 
Category & Subcategory & $\begin{array}{c}\text { Minimum value } \\
\text { of GDP per capita } \\
\text { (USD) }\end{array}$ & $\begin{array}{c}\text { Maximum value o } \\
\text { f GDP per capita } \\
\text { (USD) }\end{array}$ & $\begin{array}{c}\text { Number } \\
\text { of countries } \\
\text { in the group }\end{array}$ \\
\hline \multirow{2}{*}{ Developed } & Developed & 12235 & - & 47 \\
\hline \multirow{2}{*}{ Developing } & Upper middle income & 3956 & 12235 & 34 \\
\cline { 2 - 5 } & Lower middle income & 1006 & 3956 & 23 \\
\cline { 2 - 5 } & Low income & - & 1006 & 8 \\
\hline
\end{tabular}




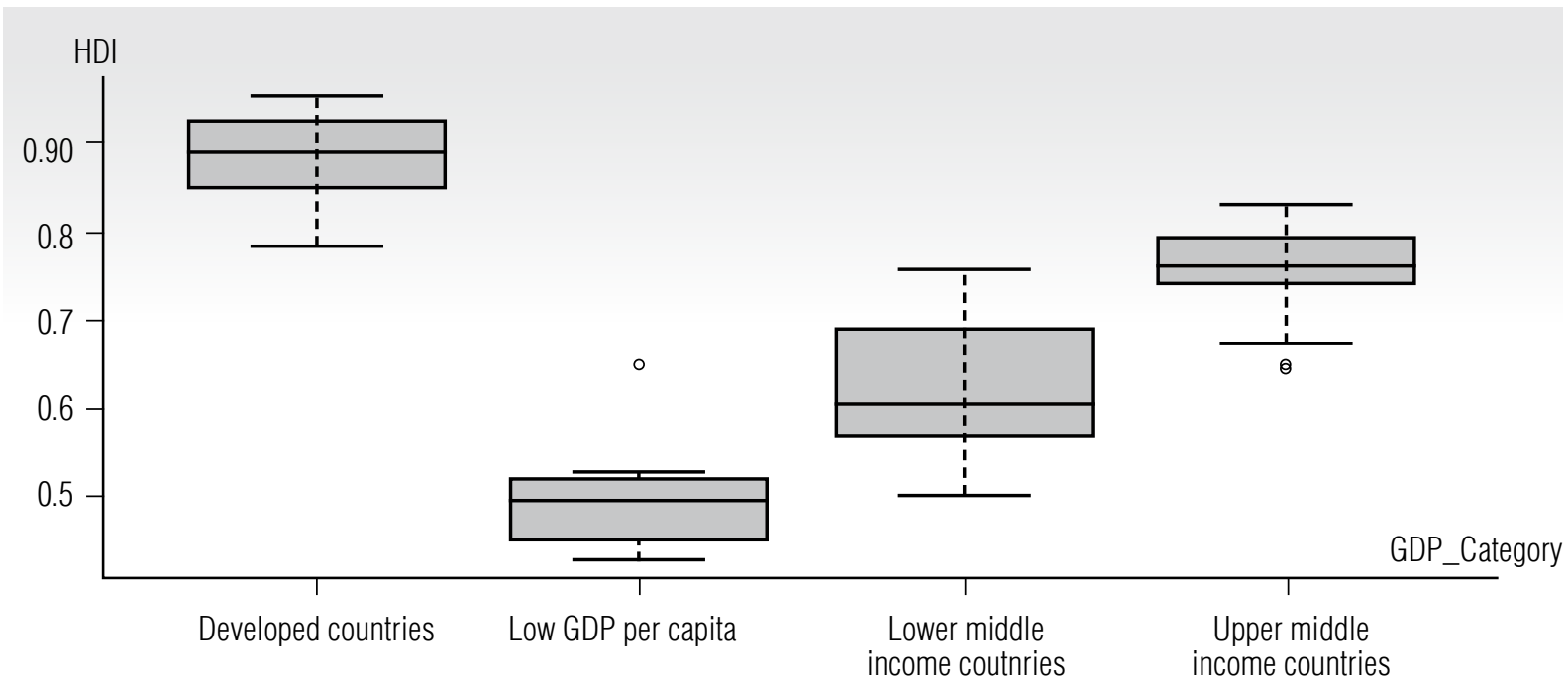

Fig. 3. HDI distribution by country group

HDI for the selected groups of countries: it can be seen that they differ, and the statistical significance of these differences is confirmed by the results of the ANOVA analysis.

The most widely used statistical method to model the dependencies between variables is linear regression analysis. However, in our case, there are problems that prevent its application. As already noted, this is multicollinearity, as well as a small sample size for each group of countries studied. Therefore, we use fuzzy regression.

When the uncertainty of the system is due to a small amount of data, measurement errors, biased estimates, and other human factors, we are dealing with a fuzzy structure of the systems under consideration. In a statistical regression model, deviations between observed values and calculated values are considered random and associated with measurement errors. In a fuzzy regression model, these deviations are assumed depending on the uncertainty of the structure of the system. Thus, fuzzy regression is applicable in cases where the data structure resists statistical analysis [16, 17].

Fuzzy number $A$ is defined by the membership function $\mu_{A}: R \rightarrow[0 ; 1]$, where $a$ is a modal value, for which $\mu_{A}: R \rightarrow[0 ; 1]$. Triangular fuzzy numbers are given by a triplet $A=\left(a_{L}, a_{C}, a_{R}\right)$, where $a_{L} \leq a_{C} \leq a_{R}$, interval $\left[a_{L} ; a_{R}\right]$ is a reference set ( $a_{L}$ is a lower bound, and $a_{R}$ is a upper bound), $a_{C}$ is a modal value [18]. The membership function of triangular fuzzy number is

$$
\mu_{A}(x)=\left\{\begin{array}{l}
0, \text { if } x \notin\left[a_{L}, a_{R}\right] ; \\
\frac{x-a_{L}}{a_{C}-a_{L}}, \text { if } a_{L} \leq x \leq a_{C} ; \\
\frac{a_{R}-x}{a_{R}-a_{C}}, \text { if } a_{C} \leq x \leq a_{R} .
\end{array}\right.
$$

A crisp number can be considered a special case of a fuzzy one, for which $a_{L}=a_{C}=a_{R}$, corresponding membership function is

$$
\mu_{A}(x)= \begin{cases}0, & \text { if } x \neq a_{C} \\ 1, & \text { if } x=a_{C}\end{cases}
$$

Let us have $m$ observations $y_{1}, \ldots, y_{m}$ of variable $Y$ and corresponding values of $n$ exogenous variables $x_{i j}, i=0, \ldots, m, j=0, \ldots, n$. A fuzzy linear regression model can be presented as

$$
\hat{Y}=A_{0}+A_{1} x_{1}+\ldots+A_{n} x_{n} .
$$


The problem of a fuzzy regression, formulated in [19], consists in the selection of fuzzy coefficients $A_{j}, j=0, \ldots, n$, which must satisfy two conditions [20]:

Fuzzy numbers $\hat{y}_{i} \in \hat{Y}$ should contain crisp observations $y_{i}$ with confidence not less than some given number $h$, i.e. the inequality $\mu_{i}\left(\hat{y}_{i}\right) \geq h$ must be satisfied;

\ Total fuzziness of $A_{j}$ should be minimal.

In our study, we set $h=0$, i.e. we replace the condition $\mu_{i}\left(\hat{y}_{i}\right) \geq h$ by the requirement that $y_{i}$ belongs to a reference set of $\hat{y}_{i}$.

In the conclusion of this section, it is necessary to make a few comments regarding the interpretation of the fuzzy model. As a result of constructing fuzzy linear regression, we get the set $\hat{y}_{i}=\left(a_{L} ; a_{C} ; a_{R}\right)$ for each observed value of $y_{i}$, but it is not an analog of the confidence interval obtained from the statistical linear regression model. A statistical confidence interval indicates confidence (e.g., 95\%) that the relationship between the variables is as the model describes. The value of the membership function $\mu_{A}(c)$ shows the certainty that the fuzzy value $A$ is equal to $c$. A high level of certainty does not mean a high probability of an event; however, if an event is uncertain, then it is impossible. In this sense, the fuzzy regression model is rougher about the situation, but that is why it is more robust when there is little information about system structure.

\section{Results}

To design the models, we used the PLRLS (Possibilistic Linear Regression combined with the Least Squares) method proposed in [21], since this allows us to obtain estimates of the target variable in the form of asymmetric triangular fuzzy numbers. All calculations were performed using the FUZZYREG package [22] for the $\mathrm{R}$ language.
The coefficients obtained for different groups of countries are presented in Table 3. Column $d^{2}(F, \hat{Y})$ presents the quality score of the model. It is calculated as the average of the distances between the actual observations $y_{i}$, converted to fuzzy triangular numbers $f_{i} \in F$, and predicted triangular numbers $\hat{y}_{i} \in \hat{Y}$. According to [16], the distance between two fuzzy numbers $A=\left(a_{L} ; a_{C} ; a_{R}\right)$ and $B=\left(b_{L} ; b_{C} ; b_{R}\right)$ is

$$
d^{2}(A, B)=\left(a_{L}-b_{L}\right)^{2}+\left(a_{C}-b_{C}\right)^{2}+\left(a_{R}-l_{R}\right)^{2} .
$$

The value determined in this way measures the proximity of two membership functions; for $d^{2}(A, B)=0$ the membership functions $A$ and $B$ are equivalent.

The $d^{2}(F, \hat{Y})$ values show that the model's confidence slightly decreases with a decrease in income, i.e. the lower the GDP per capita, the lower the accuracy of describing the dependence of human development on ICT and innovation. However, comparing these distances with the actual HDI values, it can be concluded that the reduction of accuracy is not significant.

Also, when analyzing Table 3, attention should be drawn to the fact that in all cases, except countries with low GDP per capita, the coefficients at NII and GII are the crisp numbers, and the fuzziness of the model is provided by the intercept term.

As in the case of the statistical model, the intercept can be interpreted as the value of the target variable in the case when the values of all regressors are equal to zero. In this case, this means that the intercept term sets a certain "basic" value of the fuzzy set, which for a particular observed object is adjusted by the variables describing it.

These basic values of fuzzy sets for different groups of countries are shown in Figure 4. Note that, the range increases as we move from developed countries to lower-middle-income countries but turns into a crisp number for lowincome countries. 
Coefficients of fuzzy linear regression models

Table 3.

\begin{tabular}{c|c|c|c|c} 
GDP per capita category & Intercept term & NRI & GII & $d^{2}(F, \hat{Y})$ \\
\hline Developed & $(0.5861 ; 0.6094 ; 0.6427)$ & 0.0024 & 0.0023 & 0 \\
\hline Above middle income & $(0.5139 ; 0.5786 ; 0.6189)$ & 0.0061 & -0.0033 & 0.01 \\
\hline Below middle income & $(0.1938 ; 0.2749 ; 0.3445)$ & 0.0016 & -0.0029 & 0.01 \\
\hline Low & 0.2649 & $(0.006 ; 0.008 ; 0.0016)$ & 0.0006 & 0.02 \\
\hline
\end{tabular}

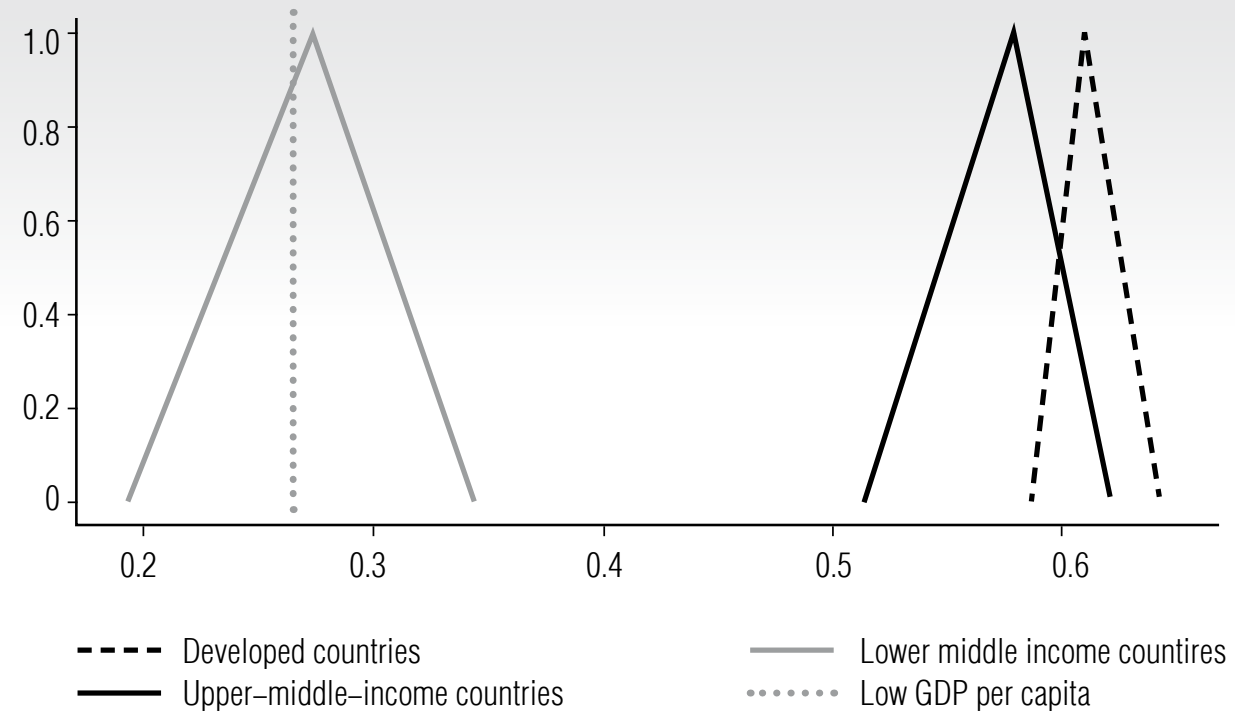

Fig. 4. Intercept terms of fuzzy regression models for different groups of countries

Interestingly, there is an overlap of intercepts for developed and upper-middle-income (UMI) developing countries. However, from the data presented in Figures 3 and 5, there is no significant overlap between these groups. This fact can be explained using the coefficients of the variables GII and NRI. For developed countries, both coefficients have similar values, which means that the states of this group are more or less balanced in developing all innovative technologies that contribute to improving the quality of life.
In the group of developing countries with upper middle income, ICT has a much more significant impact on human development. However, the coefficient of the innovation index has a negative value. This shocking result means that innovative activity in the country is associated with a fall in the quality of life.

For a deeper understanding of this phenomenon, consider a group of countries that are at the intersection of the sets of developed and developing countries with upper middle income (Table 4). This analysis is of particular 

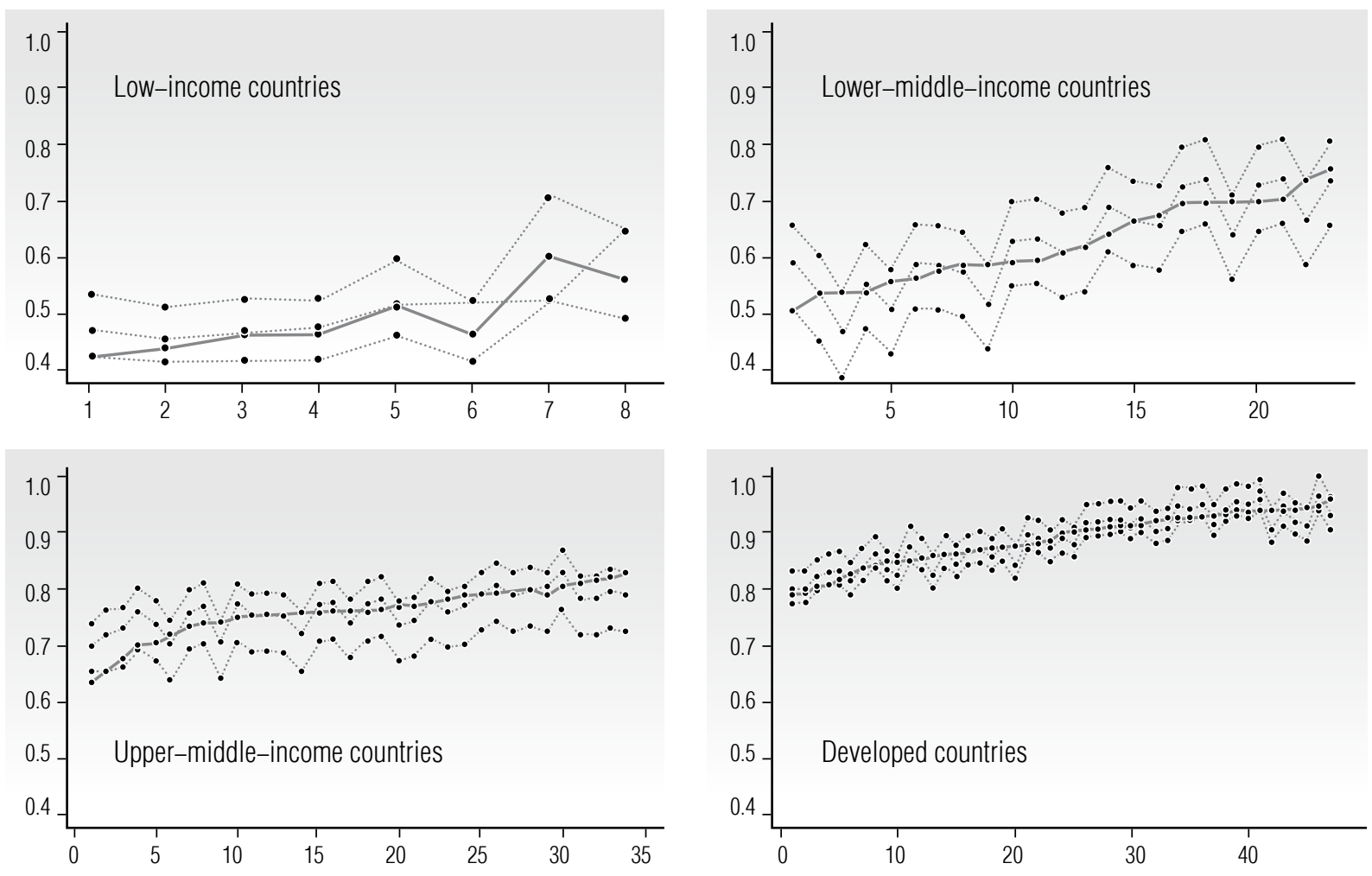

Fig. 5. Fuzzy models for all groups of countries.

The solid line corresponds to the actual HDI value, the dashed lines show the interval $\hat{y}_{i}=\left(a_{L} ; a_{C} ; a_{R}\right)$ computed based on the fuzzy regression model. The values are sorted in the ascending order of the HDI index

interest to the authors also because the Russian Federation also belongs to this group.

As follows from the data presented, Bulgaria has an NRI value comparable to Russia, while being ahead of it in terms of the innovation index. However, in the human development ranking, Bulgaria is below Russia. Argentina, losing to Russia in both exogenous variables, is ahead of Russia in HDI precisely due to the lower GII value. Similarly, Malaysia outperforms all of the countries listed in Table 4 in both the NRI and the GII but has the lowest HDI score. China is significantly ahead of Russia in technology indices but lags behind in the human development index.

Table 5 presents an analysis of the strengths and weaknesses of innovative development by GII sub-indices based on the 2019 report [15] for several countries comparable to the Russian
Federation. A "+" sign in a cell means that the compilers of the report marked this direction as a strong side, a " - " sign corresponds to a weak side. The "+/-" signs correspond to sub-indices in the assessment of which both strengths and weaknesses were recorded.

There are several features common to countries belonging to different groups:

$\downarrow$ Developing countries are characterized by less mature institutions compared to developed ones;

$\downarrow$ In developing countries (and especially in Russia) the situation with the creation of new products and services is worse. At the same time, the development of human capital and the processes of acquiring and using knowledge in developing countries are rated higher on average, but the impact of knowledge on performance is low; 


\section{Countries comparable to the Russian Federation in terms of indices}

\begin{tabular}{c|c|c|c|c|c|c}
$\begin{array}{c}\text { HDI } \\
\text { Rank }\end{array}$ & Country & Gll & NRI & HDI & $\begin{array}{c}\text { GDP per capita } \\
\text { (USD) }\end{array}$ & $\begin{array}{c}\text { Country group } \\
\text { 41 }\end{array}$ \\
\hline 42 & Croatia & 37.8 & 56.75 & 0.831 & 14910 & Developed \\
\hline 43 & Argentina & 31.9 & 51.27 & 0.825 & 11684 & Developing / UMI \\
\hline 44 & Oman & 31.0 & 52.87 & 0.821 & 16415 & Developed \\
\hline 45 & Russia & 37.6 & 54.98 & 0.816 & 11289 & Developing / UMI \\
\hline 46 & Bulgaria & 40.3 & 54.77 & 0.813 & 9273 & Developing / UMI \\
\hline 47 & Romania & 36.8 & 55.47 & 0.811 & 12301 & Developed \\
\hline 48 & Belarus & 32.1 & 50.34 & 0.808 & 6290 & Developing / UMI \\
\hline 49 & Uruguay & 34.3 & 56.4 & 0.804 & 17278 & Developed \\
\hline 50 & Kuwait & 34.6 & 53.39 & 0.803 & 33994 & Developed \\
\hline 70 & Malaysia & 42.7 & 63.76 & 0.802 & 11373 & Developing / UMI \\
\hline
\end{tabular}

UMI - Upper middle income

$\downarrow$ The strong point of developed countries is the ecological sustainability;

- The strength of all considered developing countries as opposed to developed countries is the size of the market.

Figure 6 shows the average values of the GII sub-indices for three developed countries (Croatia, Romania, Uruguay) and four developing countries with an upper middle income (Argentina, Russia, Malaysia, China), listed in Table 5. As you can see, the selected developing countries are ahead of the developed across all dimensions, except for institutions and infrastructure.

Also, for all the considered developing countries with an upper middle income, the same features of financing innovation were recorded. Public investment (as a percentage of GDP) is at a level comparable to developed countries [23], but private investment is noticeably 
Strengths and weaknesses of countries based on GII sub-indices

\begin{tabular}{|c|c|c|c|c|c|c|c|}
\hline \multirow{2}{*}{ Sub-index GII } & \multicolumn{3}{|c|}{ Developed } & \multicolumn{4}{|c|}{ Developing/ UMI } \\
\hline & Croatia & Romania & Uruguay & Argentina & Russia & Malaysia & China \\
\hline \multicolumn{8}{|l|}{ Institutions } \\
\hline Political environment & & & + & & - & & + \\
\hline Regulatory environment & & + & & - & - & - & - \\
\hline Business environment & - & & & - & & - & \\
\hline \multicolumn{8}{|l|}{ Human capital \& Research } \\
\hline Education & + & - & + & + & + & - & \\
\hline Tertiary education & - & + & - & $+1-$ & + & + & - \\
\hline Research \& Development & - & - & - & + & & + & + \\
\hline \multicolumn{8}{|l|}{ Infrastructure } \\
\hline ICT & & & + & & & & \\
\hline General infrastructure & - & & - & & & & + \\
\hline Ecological sustainability & + & + & + & & - & & - \\
\hline \multicolumn{8}{|l|}{ Market sophistication } \\
\hline Credit & & - & - & - & - & & - \\
\hline Investment & & - & - & - & - & + & - \\
\hline Trade, competition \& market scale & - & - & & $+/-$ & + & + & + \\
\hline \multicolumn{8}{|l|}{ Business sophistication } \\
\hline Knowledge workers & + & & - & + & + & - & + \\
\hline Innovation linkage & - & - & & - & & $+/-$ & - \\
\hline Knowledge absorption & - & + & $+/-$ & + & + & + & $+/-$ \\
\hline \multicolumn{8}{|l|}{ Knowledge \& Technology Outputs } \\
\hline Knowledge creation & + & - & & & + & - & + \\
\hline Knowledge impact & $+/-$ & + & + & - & - & & + \\
\hline Knowledge diffusion & - & + & + & & & + & + \\
\hline \multicolumn{8}{|l|}{ Creative outputs } \\
\hline Intangible assets & + & & & & - & $+/-$ & + \\
\hline Creative goods \& services & + & + & $+/-$ & + & - & $+/-$ & $+/-$ \\
\hline Online creativity & + & & + & & & & - \\
\hline
\end{tabular}




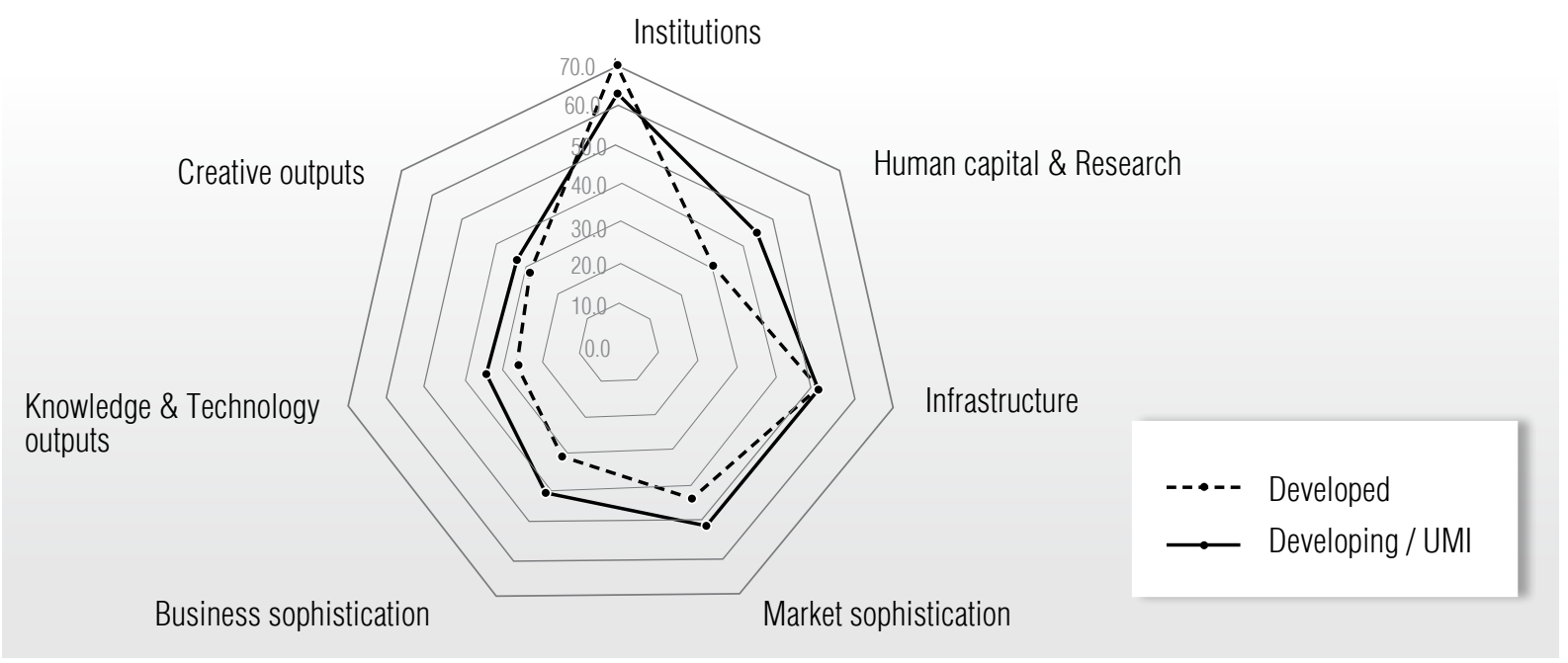

Fig. 6. Average Gll sub-indices for three developed (Croatia, Romania, Uruguay) and four developing upper-middle-income countries (Argentina, Russia, Malaysia, China)

Low return on investment in intellectual assets. For example, public investments in supercomputers was analyzed in [25]. It was shown that in Russia the return in the form of new knowledge (publications in prestigious international journals) is at a much lower level than in other countries, both developed and developing. Among the listed reasons for this are: the weak connection between science and industry, low demand for the results of scientific activities in industry, the availability of foreign science-intensive products.

$\checkmark$ A high share of the state in the economy (according to various estimates, up to $70 \%$ of GDP). However, an empirical study [26] shows that knowledge is not an efficiency factor for organizations where the state is the owner.

^ The tendency towards self-isolation, including in scientific research. In particular, the work [27] shows that the priorities of Russian researchers in the field of ICT do not coincide with the priorities of the international community, and the publications are inferior in quality to the results of foreign authors.

In addition, according to forecasts [28], the development of technology can lead to the emergence of a society controlled by the elite, not restrained by traditional values. Already, in some countries it is possible to establish almost continuous surveillance of every citizen. The information collected can be used by elites in their own interests, which do not coincide with the interests of citizens. The most prominent example of such a platform is WeChat, used by the Chinese government [29, 30].

For developing countries with lower middle income (LMI), the model (Table 3) looks similar to countries with upper middle income the positive impact of NRI and negative GII. However, in this case, the intercept term is sharply shifted to the lower values (Figure 4) and the influence of ICT on the standard of living is much less expressed. It can be stated that for these countries, all the same problems are significant as for countries with upper middle income, but they are exacerbated by the even lower quality of institutions and infrastructure. These countries include, for example, Ukraine, Moldova, and Kyrgyzstan. However, it should be noted that they are ahead of many lower-middle-income countries in terms of the human development index (Table 6). For example, Ukraine is comparable to China in terms of HDI but has noticeably lower values of NRI and GII indices and GDP per cap- 
Some developing countries at the intersection of upper middle income (UMI) and lower middle income (LMI) sets

\begin{tabular}{c|c|c|c|c|c|c} 
HDI rank & Country & GII & NRI & HDI & GDP per capita & Country group \\
\hline 67 & Armenia & 34.0 & 49.84 & 0.755 & 4212 & UMI \\
\hline 70 & China & 54.8 & 57.63 & 0.752 & 9770 & UMI \\
\hline 72 & Ukraine & 37.4 & 48.92 & 0.751 & 3095 & LMI \\
\hline 74 & Mongolia & 36.3 & 39.91 & 0.741 & 4121 & UMI \\
\hline 75 & Tunisia & 32.8 & 42.04 & 0.735 & 3447 & LMI \\
\hline 76 & Jordan & 29.6 & 46.97 & 0.735 & 4241 & UMI \\
\hline 79 & Paraguay & 27.1 & 40.55 & 0.702 & 5821 & UMI \\
\hline 80 & Moldova & 35.5 & 48.93 & 0.700 & 3227 & LMI \\
\hline
\end{tabular}

ita. This situation is primarily associated with political instability, i.e., with the quality of institutions. Still, in general, the post-Soviet countries have a higher HDI value than other countries comparable to them in terms of technological indices. This can be explained by a higher assessment of the population, which is still largely inherited from the USSR.

For low-income countries, the structure of the model changes: an intercept is a crisp number, and the fuzzy is the coefficient of the NRI. Note (Table 3, Figure 4) that the resulting intercept term (0.2649) is close to the modal value for developing countries with lower middle income (0.2749). However, for this group of countries, the influence of ICT is expressed, firstly, to the least extent, and secondly, it is described by a fuzzy number. Obviously, this is due to extremely low income, which does not allow people to purchase mobile phones and other tools of accessing information, and business and government to develop telecommunications and information services. Note also that for this group of countries, the GII index 
A more in-depth study of this phenomenon requires the joint efforts of various sciences, but already at the moment it is possible to formulate three closely related mechanisms that explain the negative effect of innovation on the standard of living:

1. With limited resources, their redistribution in favor of stimulating innovation leads to a reduction in support for health care, education, etc.;
2. Innovation systems, created in the interests of the elites, are aimed at controlling society, and not at improving the living standards of citizens;

3. Governments, even trying to develop innovative technologies in the interests of the whole of society, in the absence of transparency and competition, use the available resources ineffectively

\section{References}

1. Frey B.S., Stutzer A. (2010). Happiness and economics: How the economy and institutions affect human well-being. Princeton University Press.

2. Frijters P., Clark A.E., Krekel C., Layard R. (2020) A happy choice: wellbeing as the goal of government. Behavioural Public Policy, vol. 4, no 2, pp. 126-165. DOI: 10.1017/bpp.2019.39.

3. Drucker P.F. (1994) Post-capitalist society. Routledge.

4. Schwab K. (2017). The fourth industrial revolution. Currency.

5. Dewan S., Kraemer K.L. (2000) Information technology and productivity: Evidence from country-level data. Management Science, vol. 46, no 4, pp. 548-562. DOI: 10.1287/mnsc.46.4.548.12057.

6. Ganju K.K., Pavlou P.A., Banker R.D. (2016). Does information and communication technology lead to the well-being of nations? A country-level empirical investigation. MIS Quarterly, vol. 40, no 2, pp. 417-430. DOI: 10.25300/MISQ/2016/40.2.07.

7. Semak A. (2019) Economic development. Determination of the factors causing the "Great divergence." Resolving international economic problems with the tools of contemporary econometrics (K. Beck, ed.). Lazarski University Press.

8. Brynjolfsson E., Saunders A. (2009) Wired for innovation: How information technology is reshaping the economy. Cambridge, MA: MIT Press.

9. Atasoy H., Chen P.-Y., Ganju K.K. (2014) The effect of health IT investments on regional health care costs. Proceedings of Twenty Second European Conference on Information Systems (ECIS 2014), Tel Aviv, Israel, 9-11 June 2014, pp. 1-16.

10. Deloitte (2014) Value of connectivity: Economic and social benefits of expanding Internet access. Available at: https://www2.deloitte.com/content/dam/Deloitte/ie/Documents/TechnologyMedia Communications/2014_uk_tmt_value_of_connectivity_deloitte_ireland.pdf (accessed 25 June 2020).

11. HDI Technical Notes (2019) Human Development Report 2019: Beyond income, beyond averages, beyond today: Inequalities in human development in the 21st century. Technical Notes. Available at: http://hdr.undp.org/sites/default/files/hdr2019_technical_notes.pdf (accessed 24 June 2020).

12. UNDP (2020) United Nations Development Programme: Human Development Reports. Available at: http://hdr.undp.org (accessed 24 June 2020).

13. Stewart F. (2013) Capabilities and human development: Beyond the individual - the critical role of social institutions and social competencies. Human Development Report Office Occasional Paper, 2013/03. Available at: http://hdr.undp.org/sites/default/files/hdro_1303_stewart.pdf (accessed 24 June 2020).

14. NRI (2020) NRI 2019 Analysis. Available at: https://networkreadinessindex.org/nri-2019-analysis (accessed 25 July 2020).

15. GII (2019) Global Innovation Index Report 2019. Available at: https://www.globalinnovationindex.org/ userfiles/file/reportpdf/gii-full-report-2019.pdf (accessed 25 June 2020).

16. Diamond P. (1988) Fuzzy least squares. Information Science, no 46, pp. 141-157.

17. Radden D. (1994) Properties of certain fuzzy linear regression methods. Fuzzy Sets and Systems, no 64, pp. $361-375$. 
18. Guo P., Tanaka H., Zimmermann H.J. (1999) Upper and lower possibility distributions of fuzzy decision variables in upper level decision problems. Fuzzy Sets and Systems, no 111, pp. 71-79.

19. Tanaka H., Uejima S., Asai K. (1982) Linear regression analysis with fuzzy model. IEEE Transactions on Systems, Man and Cybernetics, no 12, pp. 903-907.

20. Sakawa M., Yano H. (1992) Multiobjective fuzzy linear regression analysis for fuzzy input-output data. Fuzzy Sets and Systems, no 47, pp. 173-181.

21. Lee H., Tanaka H. (1999) Fuzzy approximations with non-symmetric fuzzy parameters in fuzzy regression analysis. Journal of Operations Research, no 42, pp. 98-112.

22. Skrabanek P., Martinkova N. (2019) Getting started with fitting fuzzy linear regression models in $R$. Available at: https://cran.r-project.org/web/packages/fuzzyreg/vignettes/GettingStarted.pdf (accessed 9 July 2020).

23. Devadas S., Pennings P. (2018) Assessing the effect of public capital on growth. An extension of the World Bank long-term growth model. World Bank Group Policy Research Working Paper 8604. Available at: http://documents1.worldbank.org/curated/en/701811539089110745/pdf/WPS8604.pdf (accessed 17 July 2020).

24. UNICTAD (2018) World Investment Report. Available at: https://unctad.org/en/PublicationsLibrary/ wir2018_en.pdf (accessed 17 July 2020).

25. Zelenkov Y., Sharsheeva J. (2017) Impact of the investment in supercomputers on national innovation system and country's development. Communications in Computer and Information Science. Vol. 753: Parallel Computational Technologies. Switzerland: Springer, pp. 42-57.

26. Zelenkov Y. (2018) The effectiveness of Russian organizations: The role of knowledge management and change readiness. Russian Management Journal, vol. 16, no 4, pp. 513-536.

DOI: $10.21638 /$ spbu18.2018.403.

27. Zelenkov Y. (2016) Information systems through the prism of scientific publications. Open Systems, no 2, pp. 44-46 (in Russian).

28. Brzeziński Z. (1970) Between two ages: America's role in the technetronic era. New York: Viking.

29. Cockerell I. (2019) Inside China's massive surveillance operation. Wired. Available at: https://www.wired.com/story/inside-chinas-massive-surveillance-operation/ (accessed 10 August 2020).

30. Deibert R. (2020) WeChat users outside China face surveillance while training censorship algorithms. Washington Post. Available at: https://www.washingtonpost.com/opinions/2020/05/07/wechat-usersoutside-china-face-surveillance-while-training-censorship-algorithms/ (accessed 10 August 2020).

\section{About the authors}

\section{Yury A. Zelenkov}

Dr. Sci. (Tech.);

Professor, Department of Business Informatics, Graduate School of Business,

National Research University Higher School of Economics,

20, Myasnitskaya Street, Moscow 101000, Russia;

E-mail: yzelenkov@hse.ru

ORCID: 0000-0002-2248-1023

\section{Elizaveta V. Lashkevich}

Student, BSc Program "Business Informatics", Graduate School of Business, National Research University Higher School of Economics,

20, Myasnitskaya Street, Moscow 101000, Russia;

E-mail: evlashkevich@edu.hse.ru 